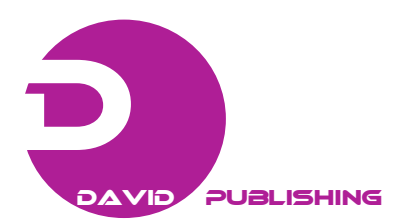

\title{
Evaluation of Hydroabrasion in a Slurry Tank
}

\author{
Mehdi Azimian and Hans-Jörg Bart \\ Chair of Separation Science and Technology, Mechanical and Process Engineering Faculty, University of Kaiserslautern, \\ Kaiserslautern D-67663, Germany
}

Received: March 19, 2013 / Accepted: June 18, 2013 / Published: December 31, 2013.

\begin{abstract}
A slurry erosion tank test rig was designed and built to investigate the erosion rates of different materials and effects of the influencing parameters on material loss and erosion profiles. A CFD (computational fluid dynamics) tool is applied to study the flow impact velocity, solid concentration and particle size effects on the erosion rate of sample plates in the liquid-solid mixture in a cylindrical tank. The MRF (multiple reference frames) method is applied to model the rotating parts inside the tank. The flow behavior and liquid-solid interactions in the slurry tank test rig are simulated and the results are validated with the experimental data. It was approved that changing the height and diameter of each rotating zone (MRF zones) have a negligible effect on simulation results. It was observed that the erosion mass losses are increasing with increase in flow velocity and sand concentration. Both variations can be predicted with a logarithmic dependence of mass loss to rotational velocity and sand concentration. The increase in erosion rate by increase in particle size was also observed for three various particle size distributions.
\end{abstract}

Key words: CFD, liquid-solid mixture, slurry tank, erosion rate.

\section{Introduction}

Erosion occurring in equipment dealing with liquid-solid mixtures such as pipeline parts, slurry pumps, liquid-solid stirred reactors and slurry mixers in various industrial applications results in operational failure and maintenance costs.

Hydro-erosion occurs in practice in two ways, one is the erosion by a cavitating liquid and the other is the erosion by solid particles entrained in liquid flow known as slurry erosion.

In slurries, the material removal from the equipment components is mainly caused by the solid particles and the material loss caused by corrosion is of relatively minor importance [1]. Stirrers in flotation cells, pumps in mining industry, pipes for crude oil recovery, turbines in hydropower engineering and instrumentation parts such as valves, bends, etc., are some examples of hydroabrasion occurrence.

Corresponding author: Hans-Jörg Bart, Prof. Dipl.-Ing. Dr. techn., research fields: extraction and multiphase flows. E-mail: bart@mv.uni-kl.de.
The machinery and equipment dealing with the liquid-solid flows can be damaged by erosion leading to low operational efficiency and short service life with frequent overhaul. In order to reduce the erosion of the machinery, the following approaches could be considered: (1) manufacturing technology; (2) selection of type and parameters of machines; (3) operational control; (4) erosion resistant design; (5) erosion resistant material; (6) predicting the erosion rates and locations.

Erosion occurs due to plastic deformation and cutting. Deformation wear takes place when the particles hit the target material perpendicular. Cutting wear is associated with parallel component of the particle impact's velocity to the specimen. Finnie [2] and Trustcott [3] have reported that erosion in slurry pipelines is mainly caused by the cutting impact of suspended solid particles, since the angle of particles impact in pipe flow is relatively small.

The material removal is determined by the laws of fluid mechanics and properties of the liquid-solid mixture and the target material properties. The flow 
properties are dependent of the component geometry, surface topography and flow rate. Here the physical properties of the two-phase mixture are affected by the solid particles concentration, size distribution, type, shape, density, hardness and sand settling velocity.

The erosion wear of a material in contact with a flowing suspension can be determined by the target material loss per unit area or loss in thickness namely as penetration rate under the dynamic and continuous action of solid particles. The unit of erosion wear is usually given per unit time or per unit solid particle throughput [4].

The wear tests in pilot plant test loops are time consuming and quite expensive, therefore it is very useful to develop a method to predict the local erosion rate in slurry handling equipment based on the measurements in the test rigs.

Altaweel [5] analyzed the phenomenon of wear using a single particle concept. Elkholy [6] has carried out a systematic study on the phenomenon of abrasion wear in slurry pumps and has shown that wear is dependent on velocity, concentration, particle diameter, impingement angle and relative hardness.

A pot tester fabricated by Gupta et al. [7] was used to conduct controlled experimental tests using equisized particles of different diameters to study the effects of velocity, concentration and particle size on the material loss and an equation for erosion rate prediction in terms of the mentioned parameters was derived. Harvey et al. [8] developed a semi-empirical model for synergy of erosion-corrosion of carbon steel in a slurry pot.

Some researchers have attached a mixer at the bottom of the slurry tank for better suspension of solid particles in the liquid phase $[9,10]$ in a homogeneous manner.

Bree et al. [11] have rotated the mixer and erosion samples in opposite rotating directions in order to avoid the relative velocity effects between the particles and erosion samples.

Investigations on the suspension of solid particles in a cylindrical tank test rig by Sharma and Shaikh [12] suggested that a propeller directing the liquid-solid mixture downwards towards the bottom of the cylindrical tank provides better uniform distribution of solid particles in comparison to upwards directing impellers.

Biswas et al. [13] observed that application of a pitched turbine blade impeller provides better suspension of solids at lower speeds compared to that of the butterfly type impeller.

Desale et al. [14] made some improvements in the design of pot tester to simulate erosion wear due to solid-liquid mixture and has found that the impeller rotational speed required for uniform distribution of solid particles in the tank varies with particle size, specific gravity and concentration of solid particles and have called this speed as the suspension speed.

CFD simulation of erosion rate and its location, together with the validation of results with experimental findings of erosion in a slurry tank is not studied in details in literature.

Moreau et al. [15] applied recently the CFDRANS simulations with the MRF technique to predict the flow behavior in a batch stirred tank reactor.

The present work reports experimental investigations of erosion of two hard metals in water-sand mixture in a slurry tank in order to validate the CFD simulations applying the MRF technique, and also studying the dependence of erosion wear to the influencing impact parameters.

\section{Experimental Setup}

The test rig as depicted in Fig. 1 contains a cylindrical glass tank having an inner diameter of 294 $\mathrm{mm}$ and height of $500 \mathrm{~mm}$. The slurry is kept in suspension by a mixer. A motor below the tank is connected to a shaft which holds the mixer. Bearings are used to support the rotating shaft and a hardened seal is provided to prevent the leakage of water from the bottom of the tank. Another motor is located at the top of the test rig connected to a shaft to rotate the erosion plates fixed to a holding arm. Fig. 2 represents 


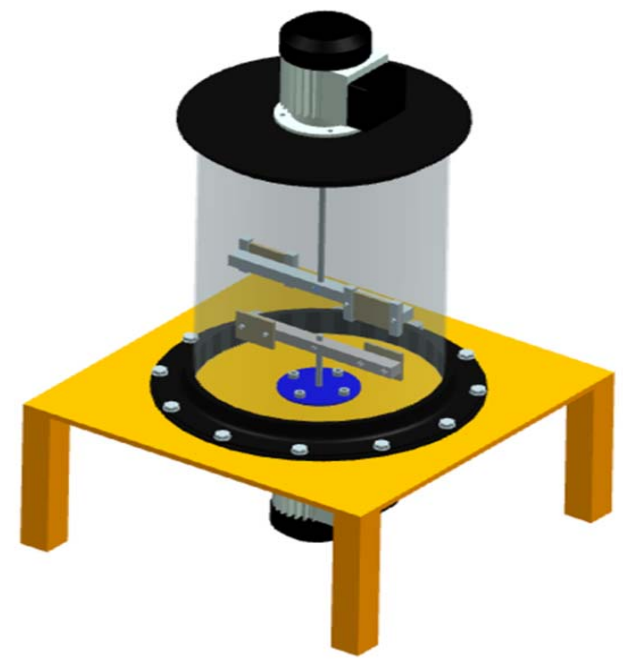

Fig. $13-D$ view of the slurry tank test rig.

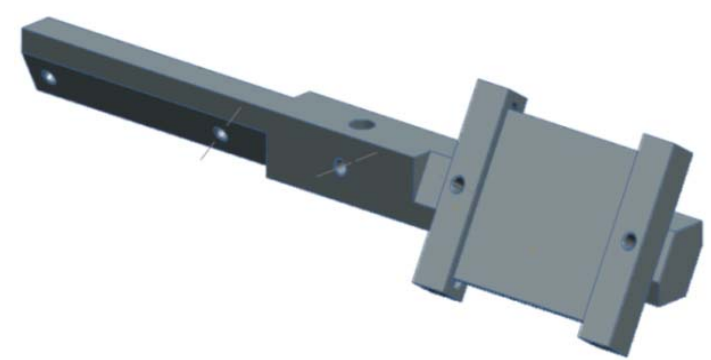

Fig. 2 3-D view of the holding arm, fixtures and an erosion plate sample.

an erosion sample plate, the fixtures holding the plate and the arm which would be connected to the shaft. As it is depicted, there is the possibility to place the plates with various angles by fabricating different holding arms. The rotating direction of upper motor should be in opposite direction compared to the bottom motor. It provides effective distribution of solid phase in liquid phase and minimizes the relative velocity effect. The erosion plates were weighted with a precise labor scale (Sartorius Company, R300S model) which has the readability of $0.1 \mathrm{mg}$, before and after each test to quantify the mass loss of each plate.

\section{Multiphase Modeling Approach}

A multiphase flow containing dispersed particles may be modeled using either the particle transport model or the Eulerian-Eulerian multiphase model. In Eulerian-Eulerian multiphase, a momentum equation needs to be solved for each representative size which becomes very costly. The particle transport model is applied in the present study since it is more flexible when there is a significant size distribution leading to different particle velocities and provides more detailed information on behavior and residence time of individual particles. However, the turbulence model used in a particle tracking simulation only applies to the continuous phases. Turbulence can affect the particles through the particle dispersion force, but the particles can have no effect on the turbulence of the continuous phase, other than indirectly by affecting the velocity field [16].

The typical sand particle size distribution is in the range of $0.1 \mathrm{~mm}$ to $0.8 \mathrm{~mm}$ in pipelines as it is depicted in Fig. 3 from experimental measurement by a HORIBA particle size analyzer which is based on laser scattering (Retsch Technology, LA950 model) at our laboratory. Pepple [17] applied the phase Doppler method for dilute, turbulent liquid-solid flow in a vertical pipe and demonstrated that in general, the particles in the range of $0.5 \mathrm{~mm}$ damp the fluid turbulence while the particles in the range of $1.0 \mathrm{~mm}$ and $1.5 \mathrm{~mm}$ are either neutral or enhance the turbulence.

A Lagrangian-Eulerian model for liquid-solid particle flow contains an Eulerian formulation for the liquid phase and the Lagrangian formulation for the particle phase together with a stochastic dispersion model to calculate the influence of liquid phase turbulence

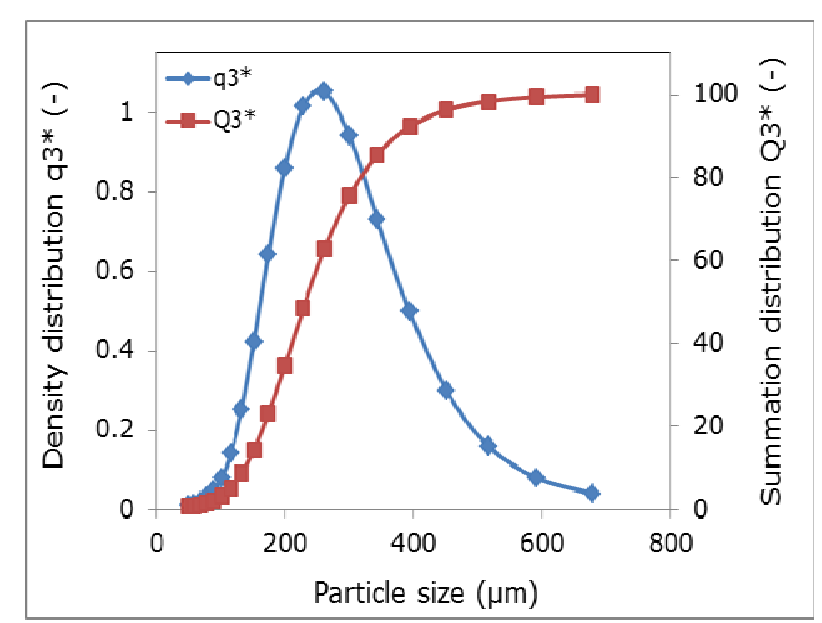

Fig. 3 Measured size distribution of sand particles. 
on the solid particle phase. It is commonly known that detailed inlet conditions play an important role in accurate Lagrangian predictions [18], so that a large number of particle trajectories are required to gain a stochastically significant solution.

In the Eulerian-Lagrangian model, the liquid phase is simulated by applying the Eulerian conservative equations of continuity and momentums. In the Lagrangian approach, the equation of any characteristic particle motion $U_{p l}$ can be written as:

$$
\frac{d \tilde{U}_{p l}}{d t}=\frac{\tilde{U}_{l}-\tilde{U}_{p l}}{\tau_{p}}+F_{p l}
$$

where $\widetilde{U}_{l}=U_{l}+u_{l}$ is the instantaneous liquid velocity, $F_{p l}$ is the external force. The response time of particle, $\tau_{p}$, is defined as:

$$
\tau_{p}=\frac{\rho_{p} D_{p}^{2}}{18 \mu f_{p}}
$$

where $f_{p}=1+0.15 \operatorname{Re}_{p}^{0.687}$ and $\left(0<\operatorname{Re}_{p}<1,000\right)$, $\rho_{p}$ and $D_{p}$ are the particle density and particle diameter, respectively. The particle trajectories are computed by:

$$
\frac{d x_{p l}}{d t}=\widetilde{U}_{p l}
$$

The two way coupling source between the liquid and solid particle phases is given by:

$$
S_{U k}^{p}=-\sum \frac{\pi}{6} \rho_{p} D_{p}^{3} \dot{N} \Delta t\left(\frac{\tilde{U}_{l}-\tilde{U}_{p l}}{\tau_{p}}\right)
$$

where the summation is carried out over all particle trajectories crossing the control volume.

\section{Application of an Erosion Model}

A comparison of erosion models was performed by calculating the erosion (material weight loss) of a square shape $44 \mathrm{~W}$ carbon steel specimen, eroded by a vertical water/sand jet tester for some various operating parameters - here the flow velocity - with four erosion models from Refs. [2, 19-21]. The results are then compared with the experimental erosion results of Wang et al. [22] for a water/sand jet set-up to investigate the erosion of hard metals. By comparison of various erosion models with experimental results as depicted in Fig. 4, it was concluded that the Grant-Tabakoff erosion model fits very well with the experimental results and thereby was selected as the appropriate erosion model for further modeling and study of erosion of rotating plates in a slurry tank.

\subsection{Grant-Tabakoff Model}

Tabakoff et al. [20, 23] has experimentally indicated that the erosion of a specimen is mostly dependent on the particle impingement angle and its impact velocity.

The uniqueness of this model compared to other erosion models of its kind is that it contains the particle impact restitution coefficient as an influencing parameter, and in particular the tangential restitution coefficient $R_{T}$ as one of the parameters affecting the erosion rate.

The following equation was developed by Grant and Tabakoff [20] to predict the erosion of the ductile materials and alloys and is defined as the ratio of the eroded mass of target material to the mass of impinging solid particles.

$$
E=k_{1} f\left(\beta_{1}\right)\left(V_{1 T}^{2}-V_{2 T}^{2}\right)+f\left(V_{1 N}\right)
$$

where, $k_{1}$ is the material constant, $f\left(\beta_{1}\right)$ is the empirical function of particle impact angle, $V_{1 T}$ and $V_{2 T}$ are respectively the tangential component of incoming particle velocity and of rebounding particle velocity. $f\left(V_{1 N}\right)$ is the component of erosion due to the normal component of velocity.

The tangential restitution ratio is defined as follows:

$$
R_{T}=\frac{V_{2 T}}{V_{l T}}=1-k_{4} V_{l} \sin \beta_{1}
$$

By inserting $V_{1 T}=V_{1} \cos \beta_{1}$, the erosion equation can be rewritten as:

$$
E=k_{1} f\left(\beta_{1}\right) V_{1}^{2} \cos ^{2} \beta_{l}\left(1-R_{T}^{2}\right)+f\left(V_{l N}\right)
$$

The effect of the particle approach angle is inserted into $f\left(\beta_{1}\right)$, and a strictly empirical approach is used to predict its behavior. The result of this analysis yields the following expression:

$$
f\left(\beta_{1}\right)=\left[1+k_{2} k_{12} \sin \left(\frac{\pi \beta_{1}}{2 \beta_{0}}\right)\right]^{2}
$$




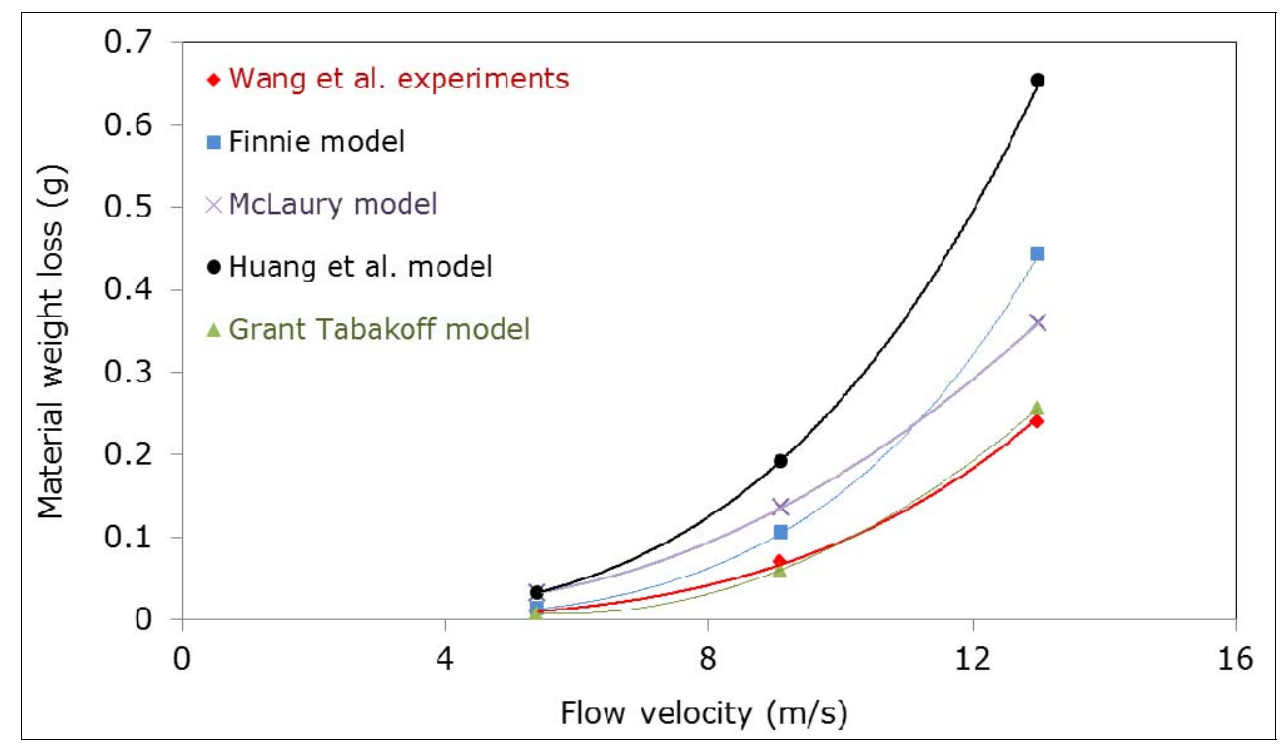

Fig. 4 Erosion prediction with various models and comparison with Wang et al. [22] exp. results.

where, $\beta_{0}$ is the angle of attack where the maximum erosion occurs, $k_{12}$ is a material constant and $k_{2}$ is defined as:

$$
k_{2}: \begin{cases}1 & \beta_{1} \leq 2 \beta_{0} \\ 0 & \beta_{1}>2 \beta_{0}\end{cases}
$$

The component of erosion resulting from normally impacting particles is expressed as:

$$
f\left(V_{1 N}\right)=k_{3}\left(V_{1} \sin \beta_{1}\right)^{4}
$$

Overall erosion rate of the wall due to the solid particles interaction with the wall is finally computed from the following equation:

$$
\dot{E}=\dot{N} \cdot m_{p} \cdot E
$$

where, $\dot{N}$ is the number rate of solid particle and $m_{p}$ is the particle mean mass.

\subsection{Finnie and Bitter Combined Model}

Finnie [2] was one of the first researchers to develop an erosion model. The proposed model for erosion of ductile metals is based on an analysis of the kinetic energy exchange mechanisms during the impact of a single solid particle where the cutting wear was the predominant mechanism. This simple erosion model is able to accurately predict ductile material erosion at relatively low impact angles. However, at high impact angles, the predictions deviated significantly from experimental values. Due to high impact angles, Finnie has suggested that material "cutting" action ceases to exist and "deformation" wear predominates. This model was later modified by Bitter [24] who considered the both effects of deformation wear and cutting wear [25].

A modified version of the Finnie-Bitter combined model equation is in the form of Eqs. (12) and (13):

$$
E R=\frac{m_{p} V_{p}^{2}}{\frac{m_{p}\left(V_{p} \sin \theta\right)^{2}}{2 \varepsilon}+(2 \phi)\left(\cos ^{2} \theta \sin (n \theta)\right)}
$$

$$
E R=\frac{m_{p}\left(V_{p} \sin \theta\right)^{2}}{2 \varepsilon}+\frac{m_{p} V_{p}^{2}}{2 \phi} \cos ^{2} \theta
$$

where, $m_{p}$ is the mass of a single abrasive particle, $V_{p}$ and $\theta$ are the local impact velocity and angle, respectively, $n$ is a numerical constant and has a value of $4.85, \phi$ and $\varepsilon$ are the energy needed to remove a unit volume of material from a body due to deformation and cutting wear, respectively and are derived from experimental data. $m_{p} / \varphi$ is the experimental constant in the cutting term and $m_{p} / \varepsilon$ is the experimental constant in the deformation term in Eqs. (12) and (13). 


\subsection{Ahlert-McLaury Model}

Wang and Shirazi $[19,22]$ predicted erosion rates on pipe bends using a CFD based approach and an erosion model was developed by their coworkers, Alhert and McLaury [19] for sand particle impacts in water which is given by Eq. (14):

$$
E R=A F_{s} V^{1.73} f(\theta) B^{-0.59}
$$

where, $F_{s}$ is the particle shape coefficient, $V$ is the local impact velocity; $A$ is an empirical constant and $B$ is the Brinell's hardness number of the test material. Alhert [26] used two functional forms of the angle dependence, with matching conditions applied at $15^{\circ}$. The dependence on impingement angle, $f(\theta)$ is given by Eqs. (15) and (16):

$$
\begin{aligned}
& \quad f(\theta)=a \theta^{2}+b \theta \quad \text { for } \theta \leq 15^{\circ} \\
& f(\theta)=x \cos \theta^{2} \sin \theta+y \sin \theta^{2}+z \\
& \text { for } 90^{\circ}>\theta>15^{\circ}
\end{aligned}
$$

\subsection{Huang Model}

Huang et al. [21] developed a material oriented erosion model taking into account the two important cutting mechanisms, namely the line cutting and area cutting. This model is written as:

$$
\begin{gathered}
E R=\frac{K_{1} m_{p}^{1.125} U_{p}^{2.25}(\cos \theta)^{2}(\sin \theta)^{0.25}}{(1+B)^{0.125} E_{B}^{0.125} \sigma_{B}^{0.7} \varepsilon_{B}^{1.2}} \\
+\frac{K_{2} E_{B}^{1.1} d_{p}^{0.05}}{\sigma_{B}^{0.98} \varepsilon_{B}^{1.44}}\left(\frac{m_{p} U_{p}^{2} \sin ^{2} \theta}{1+B}\right)^{1.15}
\end{gathered}
$$

where, $K_{1}$ and $K_{2}$ are the coefficients which depend on the materials and must be fitted from one set of experimental conditions. $B=E_{B} / E_{p}$ is defined as the stiffness ratio describing relative strength of eroded material and particle. $E_{B}, \sigma_{B}$ and $\varepsilon_{B}$ are the stiffness, hardness and elongation (ductility) of the target material, respectively. $m_{p}$ and $U_{p}$ are the particle mass and particle impingement velocity, respectively.

\section{CFD Simulation}

Geometry of the slurry tank together with the rotating arm, fixtures, mixer and sample plates as depicted in Fig. 5 were generated and finely meshed with the ANSYS-ICEM software. Grid study was performed carefully in order to obtain a fine mesh which the values of simulation results are independent of the number of mesh elements. The final mesh has totally 1,603,338 nodes and 1,525,700 elements and consists of three sub meshes. One for the rotating erosion plates, one containing the mixer and the third one for the slurry tank. The advantage is that when for instance, the orientation angle of the erosion plates is varied to investigate the angle effects on the erosion rate, the related mesh part for the erosion plates can be substituted in the final mesh, saving in time and computational efforts.

Since the final mesh contains three sub meshes, it is possible to define three computational zones in ANSYS-CFX, namely by applying the MRF method as it is shown in Fig. 6. Here, one rotating reference zone is defined for the erosion plates, one rotating reference zone for mixer and one stationary reference zone for the slurry tank. In the MRF technique, the equations are expressed in a reference frame that rotates with the rotating part speed and will be solved in a stationary mesh. This method is used since it is less resource demanding than sliding mesh approach and give quite good results. The sliding mesh method is appropriate for strong baffle/impeller interactions since the information is exchanged through the sliding interface at each time step [15].

Definition of interfaces is necessary between rotating zones and stationary zone. Since the surface mesh of rotating side and stationary side of each interface are not identical, the GGI (general grid interface) method is applied for transforming the data among the zones. We have also proved that changing the diameter and height of each of the two rotating zones containing the rotating parts have a negligible effect on simulation results.

\subsection{Simulation Parameters}

The physical properties of water and dry sand are listed in Table 1. 


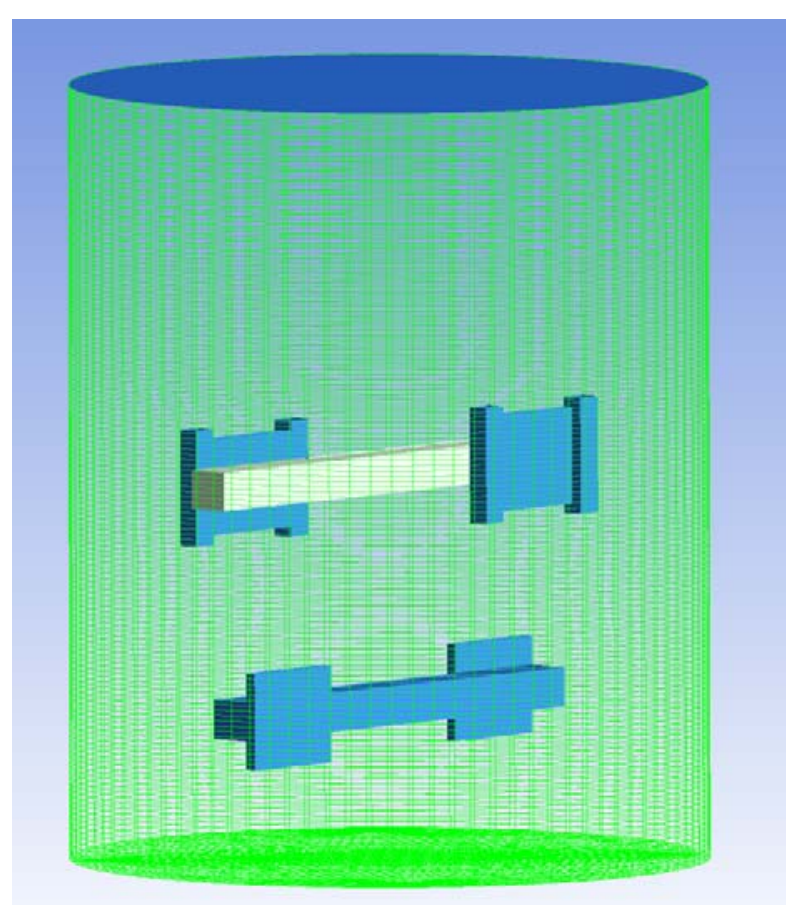

Fig. 5 Geometry modeling of the test rig.

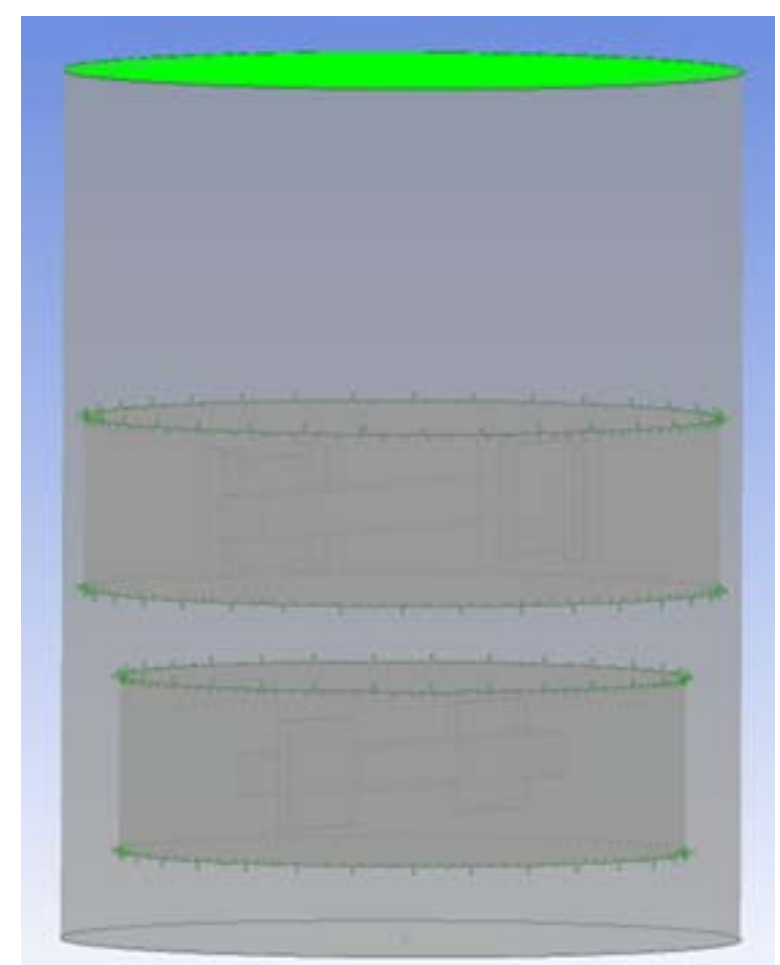

Fig. 6 MRF technique for modeling.

Table 1 Physical properties of dry sand and water.

\begin{tabular}{llll}
\hline \multirow{2}{*}{ Material } & $M$ & $\rho$ & $c$ \\
\cline { 2 - 4 } & $(\mathrm{g} / \mathrm{mol})$ & $\left(\mathrm{kg} / \mathrm{m}^{3}\right)$ & $(\mathrm{J} / \mathrm{kgK})$ \\
\hline Water & 18.02 & 997.0 & $4,181.7$ \\
Sand (dry) & 60.10 & $1,620.0$ & 800.0 \\
\hline
\end{tabular}

However, the atomic packing factor for precise determination of the bulk sand density must be taken into account. The APF (atomic packing factor) or packing fraction is the fraction of volume in a bulk structure that is occupied by atoms. For one-component materials, the APF is represented mathematically by:

$$
A P F=\frac{N_{\text {atoms }} \cdot V_{\text {atom }}}{V_{\text {unitcell }}}
$$

By assuming the $\mathrm{APF} \approx 0.7$ from literature for the sand bulk, the density of moist sand in the tank will be assumed as $2,300 \mathrm{~kg} / \mathrm{m}^{3}$ for the CFD simulations.

The CFD simulations are performed to predict how the erosion rate of rotating elements for a specified target material is changing with various influencing parameters. The important influencing parameters namely flow velocity, solid particle concentration and solid particles size were studied in the current work. The CFD results have been compared and validated with experimental results of erosion mass loss of stainless steel (with hardness of 235 HV30) and ST-50 (with hardness of $122 \mathrm{HV} 30$ ) with various rotational velocities, sand weight concentration values and solid particle size groups in the slurry tank. The experimental tests conditions for study the flow velocity and solid concentration effects are presented in Table 2 in detail.

Table 2 Experimental tests to investigate the flow velocity and sand concentration effects.

\begin{tabular}{lllll}
\hline Test & $\begin{array}{l}\text { Sand concen. } \\
(\text { wt. } \%)\end{array}$ & $\begin{array}{l}\text { Plate } \\
\text { material }\end{array}$ & $\begin{array}{l}\text { Mixer } \omega \\
(\mathrm{RPM})\end{array}$ & $\begin{array}{l}\text { Sample plates } \\
\omega(\mathrm{RPM})\end{array}$ \\
\hline 1 & 10 & Stainless St. & 200 & -200 \\
2 & 10 & Stainless St. & 160 & -160 \\
3 & 10 & Stainless St. & 120 & -120 \\
4 & 10 & Stainless St. & 80 & -80 \\
5 & 10 & ST-50 & 200 & -200 \\
6 & 10 & ST-50 & 160 & -160 \\
7 & 10 & ST-50 & 120 & -120 \\
8 & 10 & ST-50 & 80 & -80 \\
9 & 5 & Stainless St. & 120 & -120 \\
10 & 8 & Stainless St. & 120 & -120 \\
11 & 10 & Stainless St. & 120 & -120 \\
12 & 5 & ST-50 & 120 & -120 \\
13 & 8 & ST-50 & 120 & -120 \\
14 & 10 & ST-50 & 120 & -120 \\
\hline
\end{tabular}




\section{Results}

\subsection{Velocity \& Concentration Effects}

Erosion weight loss of stainless steel (Nr. 1.4301) and steel 50 (Nr. 1.0531) in water-sand mixture in the so called slurry tank has been measured at different rotational velocities and different sand concentrations. The mass loss of stainless steel and ST-50 have been evaluated in the tank test rig with $10 \%$ sand (weight concentration) and at four various rotational velocities of erosion plates and mixer plates from 80 RPM to 200 RPM and is depicted in Fig. 7. It has been observed that the erosion increases with increase in rotational velocity and the erosion mass loss of ST-50 is reasonably higher than stainless steel. This is expected since the hardness of ST-50 is lower than the hardness of stainless steel. It has also been observed that the difference of the material loss between the two material samples increases as the rotational velocity increases.

It is observed that only at rotational velocity of 80 RPM, the mass losses of both materials were reported almost to have the same value. It is observed that 80 RPM is lower than the suspension speed which is the minimum impeller rotational speed required for uniform distribution of the whole solid particles inside the tank.

The material weight losses of stainless steel and ST-50 in the slurry tank were reported at constant rotational velocity of 120 RPM for sand particles, sized from $0.1 \mathrm{~mm}$ to $0.8 \mathrm{~mm}$ and with 5, 8 and 10 percentage of sand weight concentrations and are presented graphically in Fig. 8. As depicted, the erosion mass loss increases logarithmic with increase in sand concentration and the mass loss of ST-50 is in average more than two times higher than the mass loss of stainless steel for all three tested concentration values.

CFD results of mass loss of stainless steel are compared with experimental values for different particle concentrations and rotational velocities and are shown in Figs. 9 and 10, respectively. In Fig. 9, both the steady state and transient simulation results are

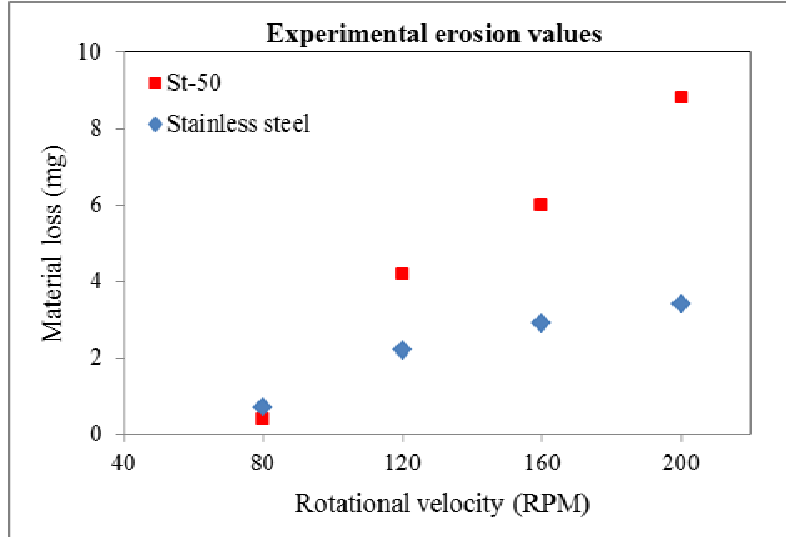

Fig. 7 Comparison of material loss of stainless steel and ST-50 versus the rotational velocity.

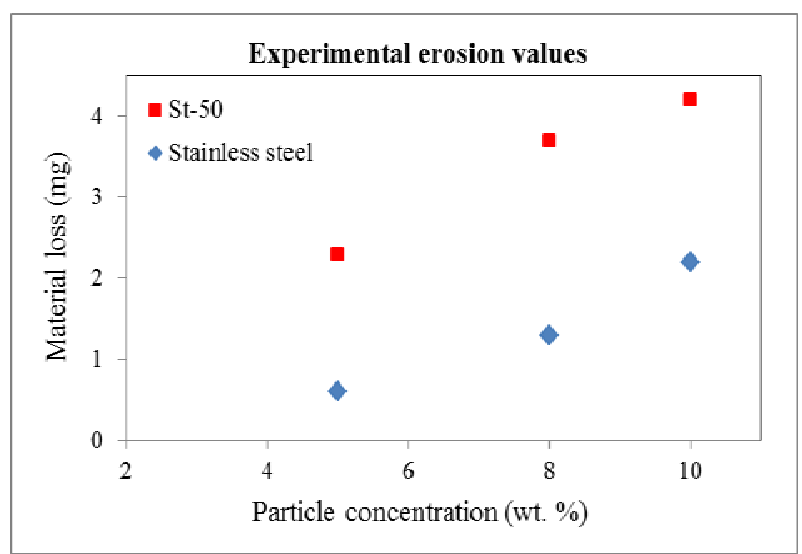

Fig. 8 Comparison of material loss of stainless steel and ST-50 versus the solid concentration.

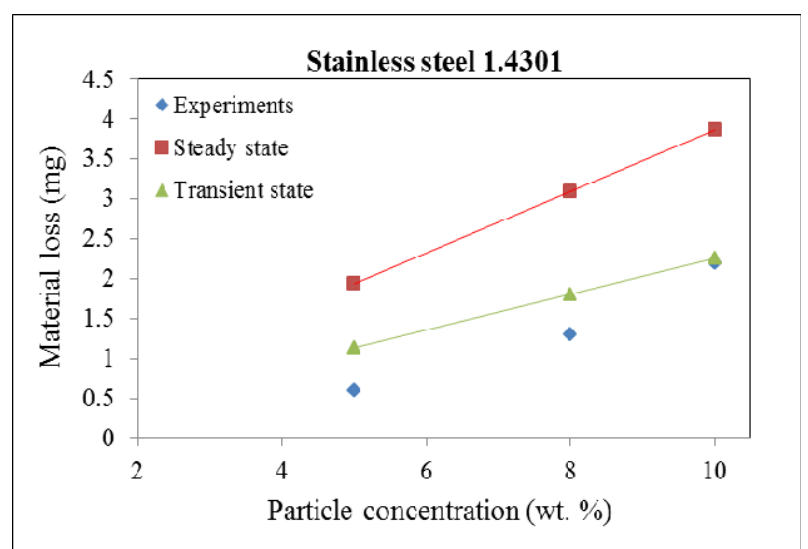

Fig. 9 Validation of CFD and exp. erosion results of stainless steel at different particle concentrations.

compared with experimental values. As it is depicted, due to the batch system of the tank, having no inlet and outlet boundary conditions, the results from steady state simulations vary higher from the experimental results. The variation between the steady state simulations 


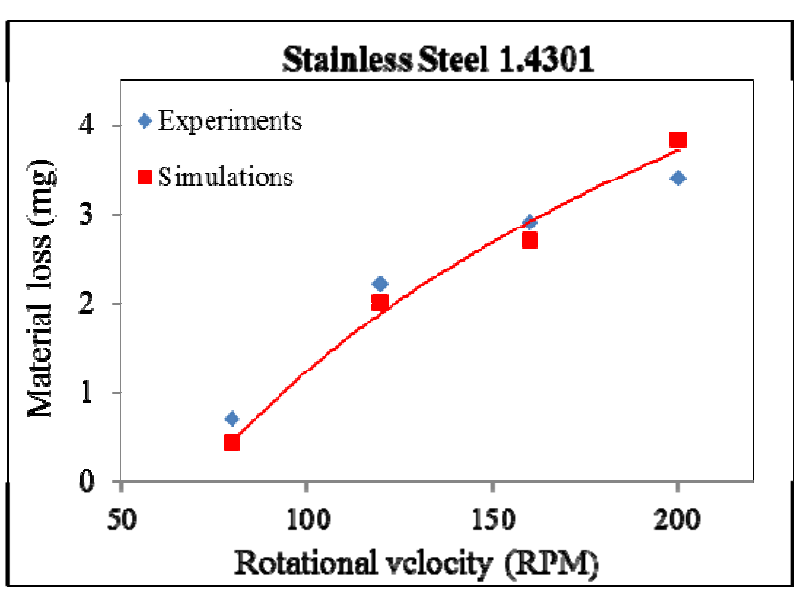

Fig. 10 CFD and exp. erosion results of stainless steel versus the rotational velocity.

and experimental results for bigger values of concentration and rotational velocities would increase further. Thereby, for other comparisons only the transient results are validated with experimental values.

The CFD results are qualitatively and quantitatively in good agreement with experimental results for both influencing parameters, however some small variations are observed. One reason could be the assumption of sand particles as solid transport particles which provides to set an injection source for the solid particles, here assumed at the center point between two rotating zones. In present study, the whole amount of sand was assumed to inject in to the domain from a central point source in the tank. Another important reason is due to complexity and variably of the flow patterns inside the tank compared to the conditions which the erosion models have been experimentally developed.

Especially, the rotating sample plates and mixer are rotating in counter direction in respect to each other, as in our experimental tests. Generally, an erosion model which was generated for instance in accordance with the experimental results from a water jet test rig, might not precisely predict the erosion rate quantities in a slurry tank test rig.

As it is observed in Fig. 11, the pressure distribution around the rotating erosion plates demonstrate that a local high pressure difference occur in the vicinity of plates causing a strong turbulent flow around the

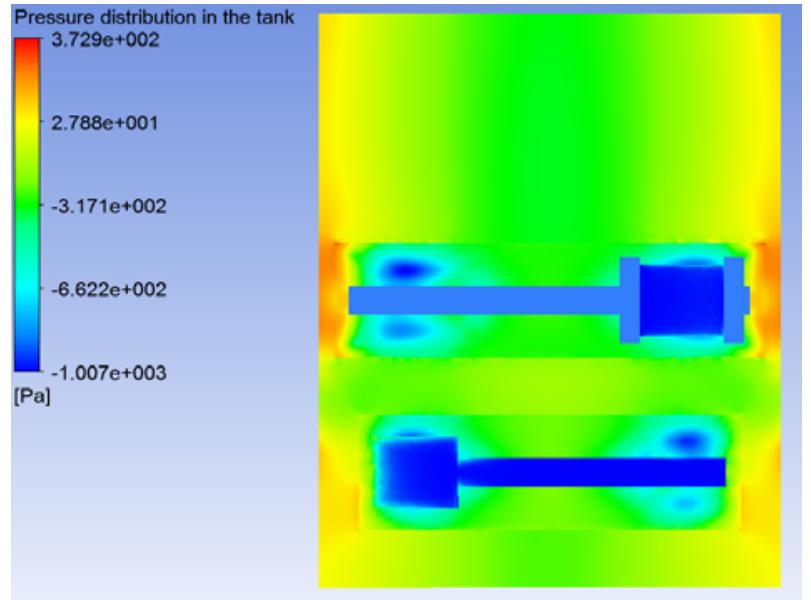

Fig. 11 Pressure distribution around the rotating elements.

erosion plates. In Fig. 12, the progress of the erosion rate over the plate as the sand particles concentration in the tank increases is demonstrated for the case of rotational velocity of 120 RPM. The erosion is mainly occurs on both edges of the plate and progress slightly towards the center of the plate as the concentration increases from Fig. 12a: 5\% to Fig. 12c: 10\% mass concentration.

CFD results of mass loss of ST-50 are compared with experimental values for different sand concentrations and rotational velocities and are presented in Figs. 13 and 14, respectively.

The CFD results are qualitatively and quantitatively in good agreement with experimental results for both cases. However, for higher rotational velocities the deviation would slightly increase.

\subsection{Particle Size Effects}

Increase in particle size, increases the erosion wear. The increase in the particle size at a constant solid concentration decreases the number of particles suspended in the mixture and at the same time increases the kinetic energy per particle impact [27, 28]. Thus, the increase in wear with an increase in particle size is generally attributed to the increase in energy available for erosion. Our experiments with three various particle size groups as are brought in Table 3, present a progressive increase in erosion rate density with increasing the particle size as depicted in Fig. 15. 


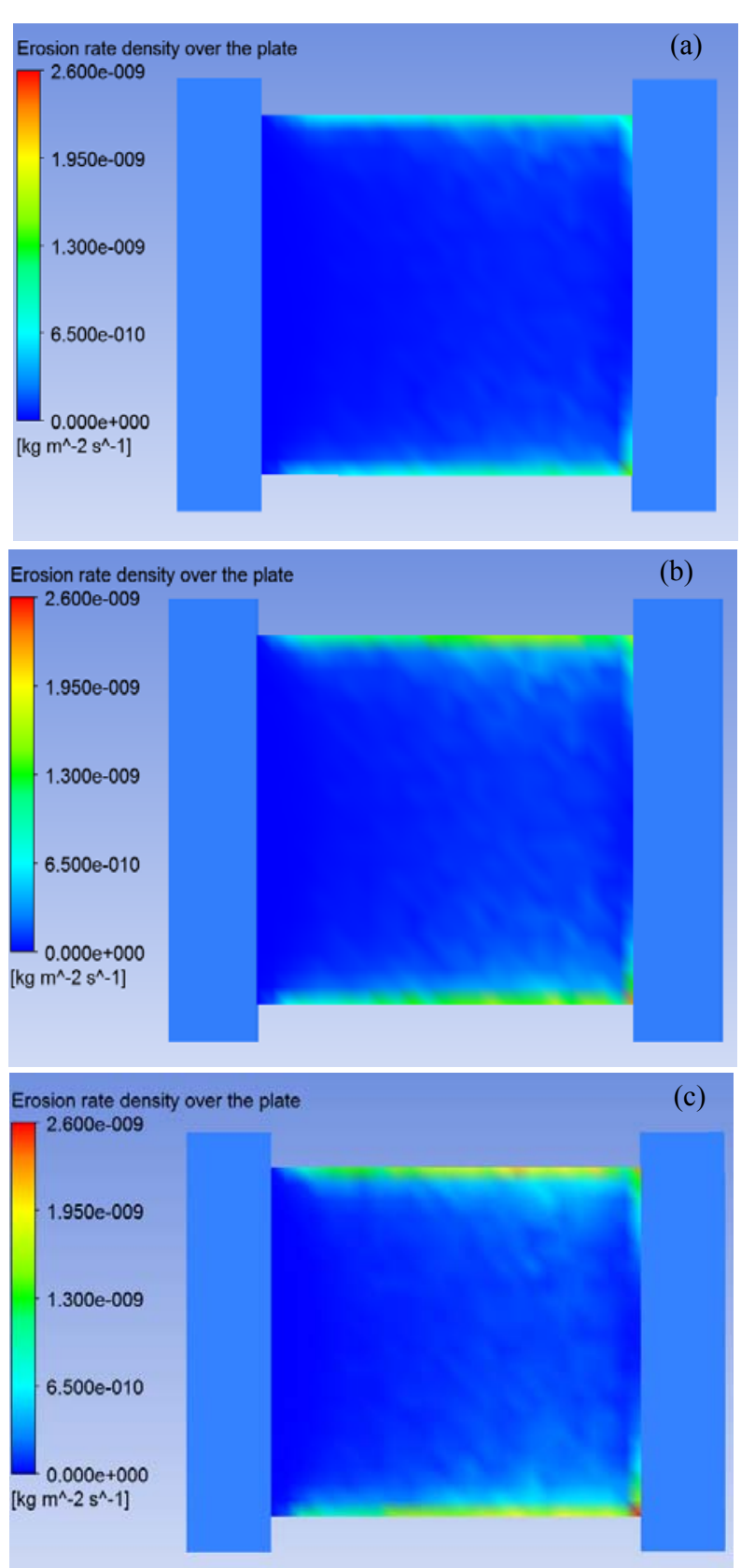

Fig. 12 Erosion values and locations with (a): 5\%, (b): $8 \%$ and (c): $10 \%$ particle concentration.

The highest deviation from the experimental results is at the third particle size group which is our standard particles used in other tests to study the velocity and concentration effects. The simulation value has a deviation of $9.621 \%$ or a difference of $0.222 \mathrm{mg}$ with respect to the experimental value. According to our experimental tests, a better mixing ratio was achieved for finer particle Groups 1 and 2, hence the better correlation to the experimental results.

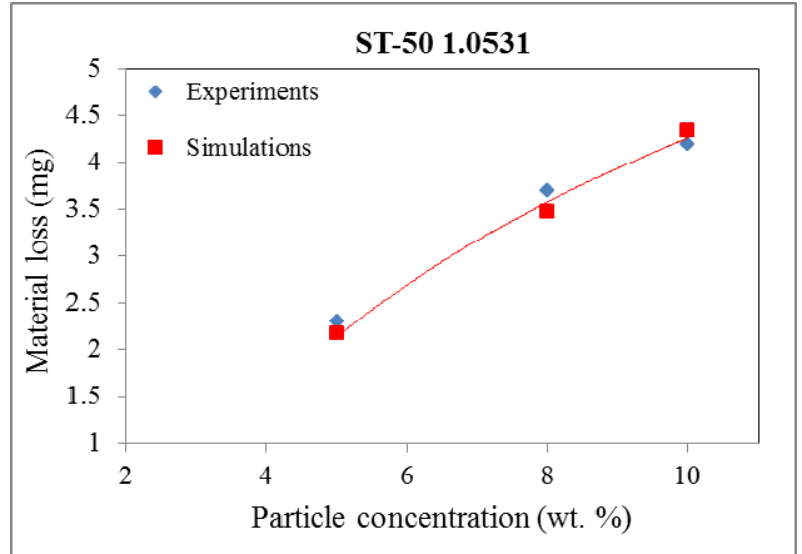

Fig. 13 Validation of CFD and exp. erosion results of ST-50 in various particle concentrations.

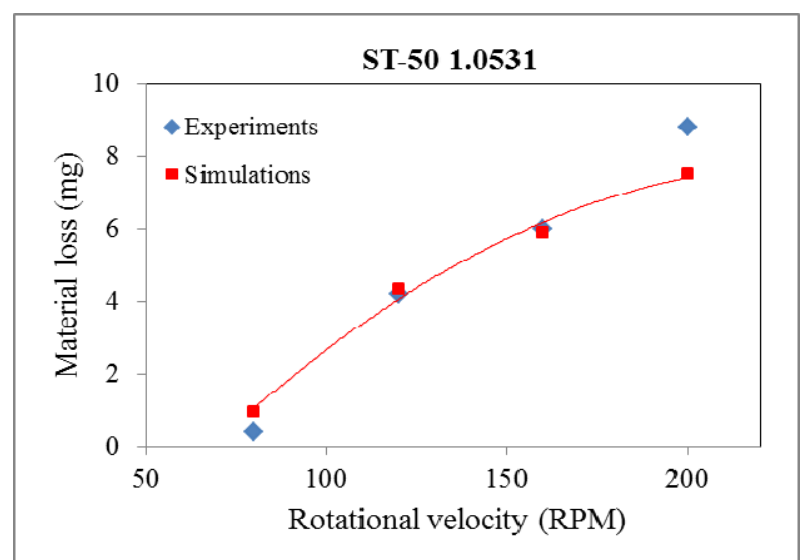

Fig. 14 Validation of CFD and exp. erosion results of ST-50 in various rotational velocities.

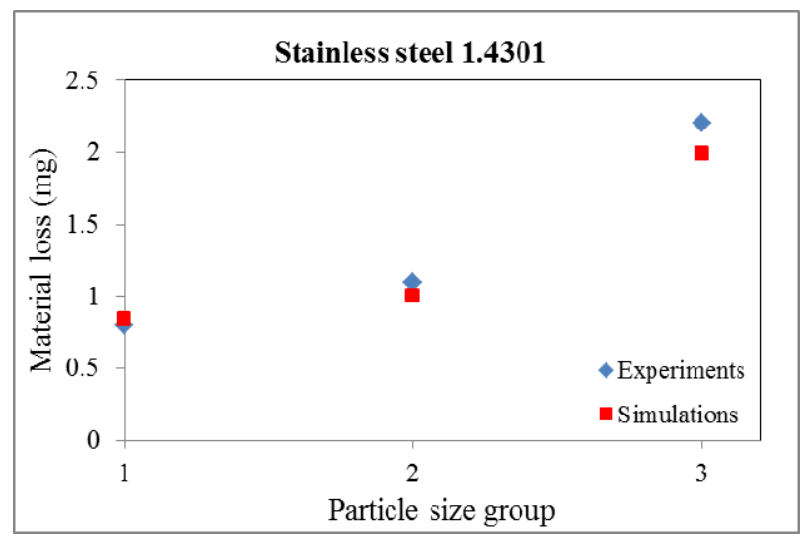

Fig. 15 Validation of CFD and exp. erosion results of stainless steel versus various particle sizes.

Table 3 Particle size groups.

\begin{tabular}{lccc}
\hline Parameter $(\mu \mathrm{m})$ & Group 1 & Group 2 & Group 3 \\
\hline Minimum diameter & 39.23 & 58.95 & 67.52 \\
Maximum diameter & 344.21 & 394.24 & 678.50 \\
Mean diameter & 141.98 & 174.75 & 263.93 \\
Standard deviation & 43.48 & 51.27 & 105.35 \\
\hline
\end{tabular}




\section{Conclusions}

A slurry tank tester has been designed and built to study the effects of erosion influencing parameters such as flow velocity, sand concentration, target material properties, target material orientation angle, etc..

In the present work the effects of flow velocity, sand concentration and particle size on erosion mass loss of two different hard metals are studied.

The method of multiple reference frames is applied to simulate the flow in slurry tank with ANSYS-CFX. The general grid interface is applied since the surface mesh of stationary and rotating side of each interface are not identical. It was observed that changing the height and diameter of each rotating zone has a negligible effect on the simulation results.

It was observed that the erosion mass losses of both materials are increasing with increase in flow velocity and sand concentration. Both variations could be predicted with a logarithmic dependence of mass loss to rotational velocity and sand concentration.

The particle size effect on the erosion rate also has been studied for three various particle size groups. The simulated results are in good agreement with experimental results for all the three influencing parameters which were studied in this work.

It was also approved that the erosion mass loss of ST-50 is reasonably higher than that of stainless steel. It is due to lower hardness of ST-50 than stainless steel and thereby lower resistance to impact effects of solid particles. A new erosion model can be also developed for the accelerated erosion mass loss of materials in a slurry tank tester when effects of all influencing parameters are studied in detail.

\section{Acknowledgments}

The authors would like to thank "Stiftung Rheinland-Pfalz für Innovation" for financial support.

\section{References}

[1] K. Sommer, R. Heinz, J. Schöfer, Verschleiß metallischer
Werkstoffe, Springer DE, 2010.

[2] I. Finnie, Erosion of surfaces by solid particles, Wear 3 (1960) 87-103.

[3] G.F. Trustcott, Wear in Pumps and Pipelines, in: L. Gittins (Ed.), BHRA Information Series No. 1, BHRA Fluid Engineering Publication, Cranfield (UK), 1980, pp. 1-22.

[4] C.A. Shook, M.C. Roco, Slurry flow principles and practice, Butterworth-Heinemann Series in Chemical Engineering, Stoneham, 1991.

[5] A.M. Altaweel, Erosion of Materials Using Recirculated Coal-Liquid Mixtures, Rep. Atlantic Research Laboratory and the National Research Council of Canada, University of Nova Scotia, Halifax, NS, 1982.

[6] A. Elkholy, Prediction of abrasion wear for slurry pump materials, Wear 84 (1983) 39-49.

[7] R. Gupta, S.N. Singh, V. Seshadri, Accelerated wear rate test rig for the predicting of erosion in slurry pipelines, in: 19th NCFMFP, IIT, Bombay, 1992, pp. C1-1-C1-4.

[8] T.J. Harvey, J.A. Wharton, R.J.K. Wood, Development of synergy model for erosion-corrosion of carbon steel in a slurry pot, Tribology 1 (1) (2007) 33-47.

[9] B.K. Gandhi, S.N. Singh, V. Seshadri, A study on the effect of surface orientation on erosion wear of flat specimens moving in a solid-liquid suspension, Wear 254 (2003) 1233-1238.

[10] B.K. Gandhi, S.V. Borse, Nominal particle size of multi-sized particulate slurries for evaluation of erosion wear and effect of fine particles, Wear 257 (2004) 73-79.

[11] S.E.M de Bree, W.F. Rosenbrand, A.W.J. de Gee, On the erosion resistance in water-sand mixtures of steels for application in slurry pipelines, in: 8th International Conference on Hydraulic Transport of Solids in Pipes, Johannesburg, South Africa, 1982.

[12] R.N. Sharma, A.A. Shaikh, Solids suspension in stirred tanks with pitched blade turbines, Chem. Eng. Sci. 58 (2003) 2123-2140.

[13] P.K. Biswas, S.C. Dev, K.M. Godiwalla, C.S. Sivaramakrishnan, Effect of some design parameters on the suspension characteristics of a mechanically agitated sand-water slurry system, Mater. Des. 20 (1999) 253-265.

[14] G.R. Desale, B.K. Gandhi, S.C. Jain, Improvement in the design of a pot tester to simulate erosion wear due to solid-liquid mixture, Wear 259 (2005) 196-202.

[15] V.S. Moreau, L.B. Errard, M. Rolland, Numerical CFD simulation of a batch stirred tank reactor with stationary catalytic basket, Chemical Engineering Journal 207-208 (2012) 596-606.

[16] ANSYSCFX Modeling Guide 12.0, Canonsburg, 2009.

[17] M. Pepple, Benchmark data for dilute, liquid-solid turbulent flow in the viscous, transitional and collisional flow regimes, in: 7th International Conference on Multiphase Flow, ICMF 2010, Tampa, FL, 2010. 
[18] C.G. Duan, V.Y. Karelin, Abrasive Erosion and Corrosion of Hydraulic Machinery, Imperial College Press, Vol. 2, 2002.

[19] X. Chen, B.S. McLaury, S.A. Shirazi, Application and experimental validation of a CFD (computational fluid dynamics) based erosion prediction model in elbows and plugged tees, J. Comput. Fluids 33 (2004) 1251-1272.

[20] G. Grant, W. Tabakoff, An Experimental Investigation of the Erosive Characteristics of 2024 Aluminum Alloy, Cincinnati University, 1973.

[21] C. Huang, S. Chiovelli, P. Minev, J. Luo, K. Nandakumar, A comprehensive phenomenological model for erosion of materials in jet flow, Powder Technology 187 (2008) 273-279.

[22] M.H. Wang, C. Huang, K. Nandakumar, P. Minev, J. Luo, S. Chiovelli, Computational fluid dynamics modeling and experimental study of erosion in slurry jet flows, Int. J. Comput. Fluid Dynamics 23 (2) (2009) 155-173.
[23] W. Tabakoff, R. Kotwal, A. Hamed, Erosion study of different material by coal ash particles, Wear 52 (1979) 161-170.

[24] J.G.A. Bitter, A study of erosion phenomena part I, Wear 6 (1) (1963) 5-21.

[25] A. Gnanavelu, N. Kapur, A. Neville, J.F. Flores, N. Ghorbani, A numerical investigation of a geometry independent integrated method to predict erosion rates in slurry erosion, Wear 271 (2011) 712-719.

[26] K.R. Ahlert, Effects of particle impingement angle and surface wetting on solid particle erosion on ANSI 1018 steel, M.Sc. Thesis, University of Tulsa, USA, 1994.

[27] G.R. Desale, B.K. Gandhi, S.C. Jain, Particle size effects on the slurry erosion of aluminum alloy (AA 6063), Wear 266 (2009) 1066-1071.

[28] R.S. Lynn, R.K. Wong, H.M. Clark, On the particle size effect in slurry erosion, Wear 149 (1991) 55-71. 